\title{
Evaluation of antigenic load in pregnant sows and identification of isoimmunization markers in offspring to increase productive and reproductive indicators for obtaining biologically safe organic products
}

\begin{abstract}
Alexander Agarkov ${ }^{1, *}$, Angelina Shulunova ${ }^{1}$, Nikolay Agarkov ${ }^{1}$, Alexander Sidelnikov ${ }^{1}$, and Irina Nekrasova ${ }^{1}$
\end{abstract}

${ }^{1}$ Stavropol State Agrarian University, Serov st., 523, 355019 Stavropol, Russia

\begin{abstract}
Immunological aspects of the relationship in the functional system "mother-fetus" are consciously important both in the scientific and practical direction of the life of living organisms. The formation of the main parameters of isoimmunization is an equivalent aspect in relation to the basics of the formation of artificial tolerance mechanisms. Changes in immunological reactivity to viral and bacterial antigens may cause increased susceptibility to infectious diseases. Different levels of this condition in newborn and adult animal organisms should be based on the fact that the fetus and newborn after birth first comes into contact with the antigen, while the adult body already has partial sensitization. Chronic carrier of pathogens in animals and their influence on the spread of the infectious process is an urgent problem of modern veterinary medicine. The possibility of vaccination in newborns is limited by the presence of maternal antibodies that have an immunosuppressive effect.The immunological relationship between the fetal mother's body in a noninbred population should be considered in two aspects: the effects caused by maternal antigens in the fetus; the effect of fetal antigens on the mother's body. Level of functional reserves of the pregnant body is important in the prevention of intrauterine infection.
\end{abstract}

\section{Introduction}

Productive animal husbandry has large losses of livestock in the process of its breeding and operation. It is important to find out the reasons for such significant losses. Significant losses (young animals of early age) are caused by violation of the conditions of the intrauterine period of development [1-16]. They are accompanied by the birth of offspring with signs of reduced viability, high morbidity and mortality.

\footnotetext{
*Corresponding author: agarkov_a.v@mail.ru
} 
Due to the fact that violations of the conditions of intrauterine development are determined in animals at a later date, the effectiveness of preventive measures is very difficult [3-15].

Early detection of individuals with reduced viability allows to prevent the possibility of diseases in the early stages of ontogenesis. Therefore, the problem of effective assessment of immunological reactivity in the functional system "mother-fetus-newborn" becomes relevant [4-17].

He aim of the study is to evaluate the mechanisms of isoimmunization in the "motherfetus-newborn" system, its specific properties under the direct influence of natural antigenic stimuli [10-12].

The pathology of antenatal animal development has not been sufficiently studied. Antenatal pathology of animals is more often manifested in the form of congenital malformations (anomalies) of development. Congenital defects are usually called malformations [1-3] that occurred during the period of intrauterine development. However, congenital malformations are also observed during postnatal development as a result of disruption of further organ formation in animals. Ugliness refers to pronounced persistent morphological changes in tissues and organs that disfigure the body or part of it.

By the nature of clinical manifestation, congenital malformations of antenatal development of animals can be compared with an iceberg. Only the "tip of the iceberg" in the form of a small number of symptoms due to the abnormal development of gametes, zygotes, embryos and fetuses is available for direct observation [5]. The rest of the mass of signs of abnormal intrauterine development is hidden from the eyes of the researcher.

Although accurate statistics on the prevalence of congenital defects in farm animals are not yet available, it is nevertheless clear that they are widespread and are one of the most important constraints on the development of livestock production. An indirect confirmation of this conclusion is the data on animal infertility, abortion, the frequency of birth of calves, lambs and hypotrophic piglets with anatomical and physiological defects in the lungs, stomach, intestines and other organs.

At the suggestion of the WHO scientific group, congenital malformations are divided into hereditary, exogenous and multifactorial [4-7].

The body of a pregnant animal is an external environment for zygote, embryo and fetus. The maternal body provides the needs of the embryo for nutrients and plastic material, and the female's sexual system (uterus) serves as its habitat. In relation to the embryo, the maternal organism is a "supra-organised" biological system [6-8].

Analysis of literature data [1-5] and results of own studies and observations suggests that the cause of congenital malformations can be negative changes in biogeocenoses and their component components. The pathological effect also causes negative changes in the biological system of a higher rank - the animal population. Increased population density, impaired intra-population relationships between dominant (leaders), subdominants, and subordinate animals can cause not only changes in embryo development, but also termination of pregnancy (abortion).

The main phases of antenatal development are:

- the pro-genesis which is beginning with the moment of formation and maturing of female and men's gametes and coming to an end with fertilization of an ovum and formation of zygotes;

- blastogenesis involving the development of blastomers, morules and embryonoblasts;

- embryogenesis characterized by the formation of organs in the embryo;

- fetal (fruiting) period, during which the differentiation of the most important organs of the fetus is completed and its rapid growth occurs. 
We believe that the prevention of congenital malformations and diseases of young animals consists in the regulation and optimization of processes occurring in the motherfetus-newborn functional system.

\section{Materials and methods of research}

Experimental studies were conducted on sows of a Large White breed on the farms in the Kurskoy district of the Stavropol territory.

Test group included animals with increased antigenic load (hyperimmunization). The control group included animals subjected to the traditional vaccination scheme adopted on the farm.

To study the receptors/markers of lymphocytes in animals from the test and control groups, blood was collected for flow cytometry. The analysis of lymphocyte receptors was performed by double immunofluorescence using a panel of monoclonal antibodies marked with phycoerythrin. Lymphocyte populations were identified by the following combinations: tags: CD45/CD14, CD3/ the lymphocytes content CD19 and receptors CD3/CD56,

Blood tests for $\mathrm{CD}+$ receptors were performed by standard methods after 1, 2, 6, 8, 12 weeks, using the method of two-color flow cytometry. The obtained data were processed using nonparametric analysis.

The main parameters of the antigenic relationship in the functional system "motherfetus-newborn" were determined in the reactions of complement binding, precipitation in the gel and based on the phenomenon of hemagglutination.

All studies were performed using the blood serum of the mother's body as a source of antibodies against the blood sera of their offspring.

Antigenic loading was carried out by vaccination of pigs with live virus-VGNKI vaccine against Aujeski's disease and VR2 vaccine against erysipelas. The drugs were administered according to the instructions for their use without prior mixing, with different syringes, since one of them is injected strictly subcutaneously, and the otherintramuscularly. 20 repair pigs aged 6-8 months (Group 1) were vaccinated simultaneously against Aujeski's disease and erysipelas; 12 sows were injected in the first half of gestation (Group 2); 8 sows were injected in the second half of gestation. The third group of 10 heads served as a control group.

The resulting offspring were divided into three groups according to the principle of analogues. The first group included 10 individuals with low titers of complement-binding antibodies in their blood serum (1: 5-1: 80). The second group consisted of 10 piglets, in whose blood serum antibodies were detected in large titers (1: 40-1: 80). The third group served as a control group..

Electronic thermometry was performed for the first three days after immunization, and the animals were followed up for 5 months. In sows of all these groups, during the first 2-3 days after vaccination, an increase in body temperature by $0.2-0.4^{0} \mathrm{C}$ was observed, that is, within the limits allowed by the instructions for the use of drugs.

\section{Results}

The change in immunological reactivity in pregnant animals was characterized by the formation of the maximum dilution of the immune complex (Table 1). Hyperimmune serum formed an immune complex with isoantigens, which bound the entire complement introduced into the reaction when diluting the serum at a dilution of 1:10-1:20. 
Table 1. Serological comparison of isoantigens in pregnant sows of different farrowing multiplicity using antiserum

\begin{tabular}{|c|c|c|}
\hline \multirow{2}{*}{$\begin{array}{c}\text { Animal group } \\
\mathrm{n}=30\end{array}$} & \multicolumn{2}{|c|}{ Antibody titer } \\
\cline { 2 - 3 } & $\begin{array}{c}\text { in complement binding } \\
\text { assay (CBA) }\end{array}$ & $\begin{array}{l}\text { in nonspecific reaction } \\
\text { of the antigen phase }\end{array}$ \\
\hline Test group & $1: 20-1: 40$ & $1: 32-1: 64$ \\
\hline Control group & $1: 640-1: 280$ & $1: 10-1: 24$ \\
\hline
\end{tabular}

The difference in response to the antigen was significant in the test groups of individuals with the lowest farrowing multiplicity (2-3 farrowings) to the groups of 5-7 farrowings. Based on the data above, we believe that cross-reactions at low dilution indicate the presence of an isoimmunization effect, but at the same time a large difference in response (1:640-1:280 and 1:20-1:40 in complement binding assay and 1:32-1:64) indicates significant isoantigenic loads in the offspring.

Controlling the effect of autoantibodies detected in the offspring, we examined the blood sera of piglets in the reaction of long-term complement binding assay to the maternal antigen for 4 months every 30 days. The results of the studies are presented in Tables 2 and 3 .

Table 2. Results of the study of blood sera of test groups piglets in the long-term complement binding assay

\begin{tabular}{|c|c|c|c|c|c|}
\hline $\begin{array}{c}\text { animal } \\
\text { number }\end{array}$ & $\begin{array}{c}\text { before the } \\
\text { birth }\end{array}$ & in 30 days & in 60 days & in 90 days & $\begin{array}{c}\text { in } 105 \\
\text { days }\end{array}$ \\
\hline 182 & $1: 320$ & $1: 160$ & $1: 80$ & $1: 10$ & - \\
\hline 174 & $1: 80$ & $1: 80$ & $1: 40$ & $1: 5$ & - \\
\hline 245 & $1: 640$ & $1: 160$ & $1: 80$ & $1: 20$ & - \\
\hline 277 & $1: 640$ & $1: 160$ & $1: 80$ & $1: 20$ & - \\
\hline 198 & $1: 640$ & $1: 80$ & $1: 40$ & $1: 20$ & - \\
\hline 184 & $1: 80$ & $1: 80$ & $1: 40$ & $1: 20$ & - \\
\hline 201 & $1: 160$ & $1: 80$ & $1: 40$ & $1: 5$ & - \\
\hline 195 & $1: 580$ & $1: 160$ & $1: 40$ & $1: 5$ & - \\
\hline 137 & $1: 580$ & $1: 320$ & $1: 80$ & $1: 20$ & - \\
\hline 140 & $1: 320$ & $1: 320$ & $1: 160$ & $1: 80$ & $1: 80$ \\
\hline
\end{tabular}

Table 3. Results of the study of blood sera of control group piglets in the long-term complement binding assay

\begin{tabular}{|c|c|c|c|c|c|}
\hline $\begin{array}{c}\text { animal } \\
\text { number }\end{array}$ & $\begin{array}{c}\text { after the } \\
\text { birth }\end{array}$ & in 30 days & in 60 days & in 90 days & in 105 days \\
\hline 273 & $1: 5$ & - & - & - & - \\
\hline 269 & - & - & - & - & - \\
\hline 551 & - & - & & & \\
\hline 279 & - & $1: 10$ & - & - & - \\
\hline 283 & - & - & - & - & - \\
\hline 300 & - & - & - & - & - \\
\hline 304 & - & $1: 6$ & - & - & - \\
\hline 257 & - & - & - & - & - \\
\hline 251 & - & - & - & - & - \\
\hline 276 & - & - & - & - & - \\
\hline
\end{tabular}

As can be seen from the data in Table 3, in 7 piglets of the first group, the complementbinding antibodies disappeared after 30 days. In 3 animals, a decrease in antibody titers was 
observed immediately after the birth, but we detected antibodies in their blood serum for 60-90 days. Three piglets that still responded positively to the long-term complement binding assay were found to have traces of antibodies after 60 days. According to the results of studies, all 10 piglets from the test group were assigned to animals with signs of isoimmunization in the fetal period.

In several piglets ( 7 heads) of this group, the titers of complement-binding antibodies decreased (Table 2.), but did not disappear during the entire observation period (4 months). In the blood serum of individuals from the control group, antibodies in diagnostic titers were not detected during the entire observation period.

In subsequent experiments, it was found that sows before pregnancy or in its early stages, transmit a state of specifically reduced reactivity to offspring, and this was not observed in piglets obtained from females that did not have an isoimmune effect. Based on all these data, we concluded that the state of specifically reduced reactivity that occurs in sows after the introduction of live vaccines is due to the presence of a blocking factor with unchanged reactivity of the population of immunocompetent cells (Figure 1).

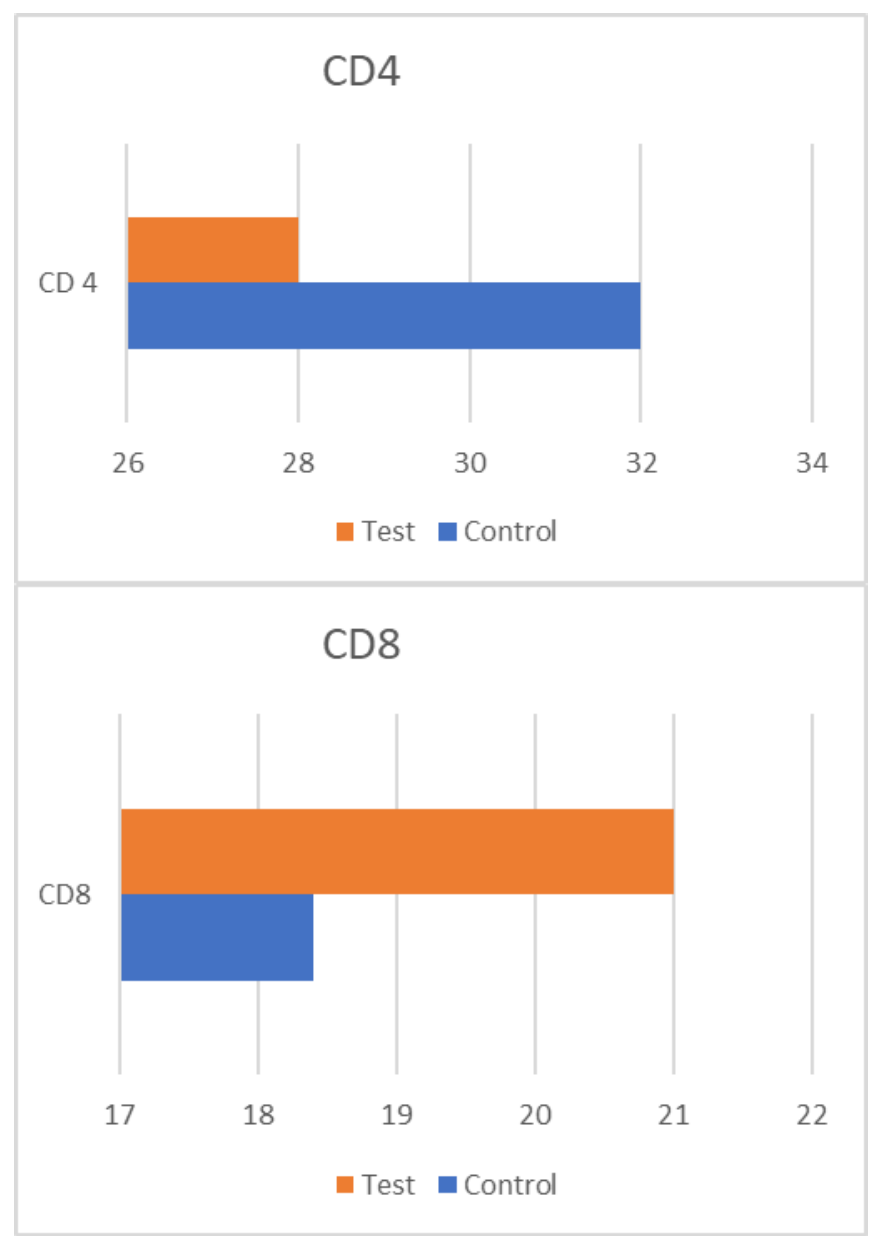




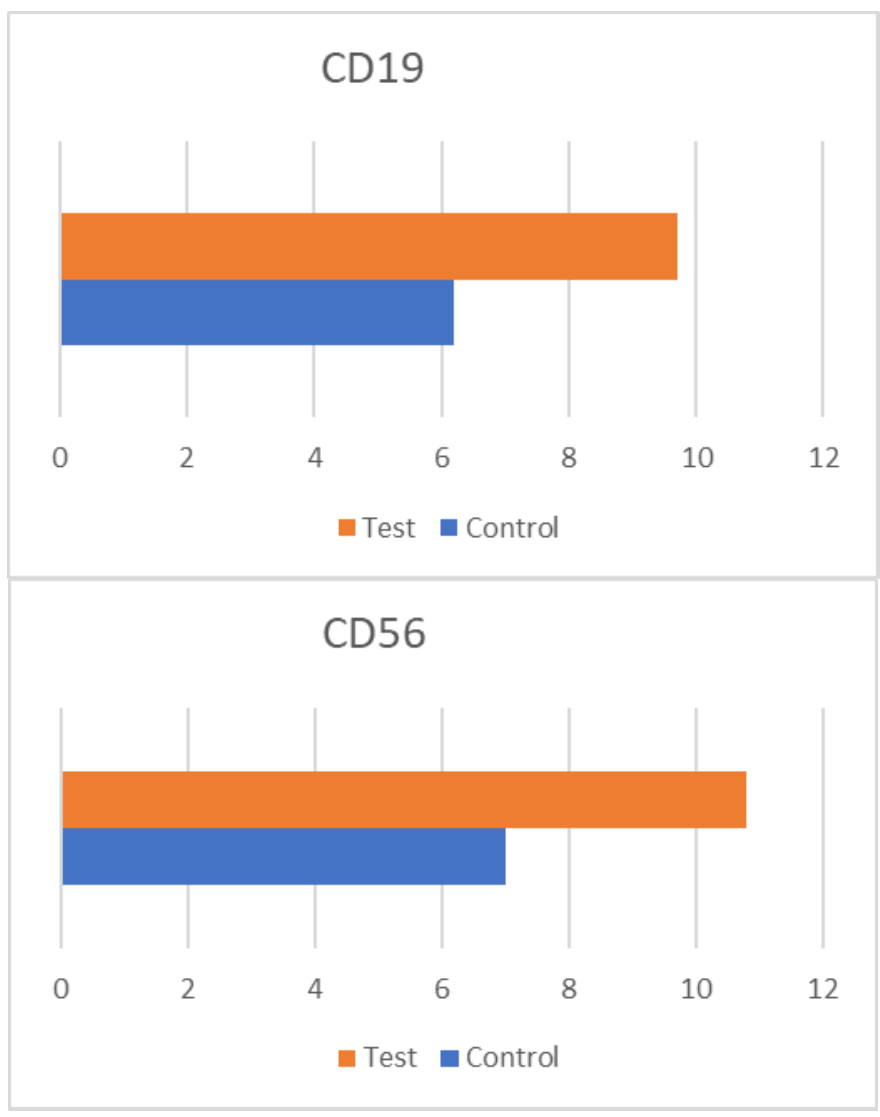

Fig. 1. Lymphocytic markers of test and control groups of animals.

Cytochemical analysis of blood cells of newborns piglets from the test groups was characterized by reduced activity. There were significant differences in the level of lymphocyte markers in the control and test groups $(\mathrm{P}<0,05)$. The difference with the trend of dynamic increase CD4 is revealed $(\mathrm{P}<0,05)$. At the same time, a significant decrease in the CD4/CD8 ratio was found, which characterizes cell-mediated suppression of immunity. The obtained data give grounds to believe that the state of specific areactivity in animals in these cases is determined, at least in part, by the presence of humoral blocking factors in their body - isoantibodies.

In newborn piglets from the control group, the results of cytochemical studies of peripheral blood lymphocytes and neutrophils indicated energy intensity, which contributed to maintaining high energy consumption in the early neonatal period for adaptation processes.

\section{Conclusions}

1. The absence of titers of complement-binding antibodies in the offspring indicates the full development of the fetoplacental complex during pregnancy.

2. Low titers and long-lasting persistent isoantibodies are a causal factor of violation of placental conditions and manifestations of the effect of isoimmunization in the fetus. 
3. The change in the immunological relationship of the functional system "mother-fetus" in the process of isoimmunization is a criterion for the state of specific immunological areactivity in newborn piglets.

\section{References}

1. M. Milovanovic, K. Dietze, V. Milicevic, S. Radojicic, M. Valcic, T. Moritz Hoffmann, BMC Vet Res 15, 56-61 (2017) doi: 10.1186/s12917-019-1831-y

2. A. Brunse, P. Worsoe, S.E. Pors, K. Skovgaard, P.T. Sangild, Shock 51, 337-347. doi: 10.1097/SHK.0000000000001131

3. M. Dennis, J. Eudailey; J. Pollara, A.S. McMillan, K.D. Cronin, P.T. Saha, Coadministration of CH31 Broadly Neutralizing Antibody Does Not Affect Development of Vaccine-Induced Anti-HIV-1 Envelope Antibody Responses in Infant Rhesus Macaques 93, 64-78 (2013) doi: 10.1128/JVI.01783-18

4. X. Du, S. Chang, W. Guo, S. Zhang, Z.K. Chen, Progress in Liver Transplant Tolerance and Tolerance-Inducing Cellular Therapies, Frontiers in Immunology 11(1326) (2020) doi: 10.3389/fimmu.2020.01326

5. G. Iraola, R. Perez, L. Betancor, A. Marandino, C. Morsella, A. Mendez, BMC Veterinary Research 12, 103-111 (2011) doi: 10.1186/s12917-016-0913-3

6. M. Seguel, D. Perez-Venegas, J. Gutierrez, Physiological and Biochemical Zoology 92, 326-338 (2014) doi:10.1086/702960

7. D. Karussis, P. Petrou, Immunologic Research 92, 642-648 (2015) doi:10.1007/s12026-018-9032-5

8. J. Dai, X. Yang, Y. Zhu, C. Wang, Cell Therapy Against Cerebral Stroke Immune tolerance induced by decitabine combined with multiple allogeneic bone marrow mononuclear cell infusion 50, 3797-3803 (2017) doi:10.1016/j.transproceed.2018.05.019

9. D. Karussis, P. Petrou, Immunologic Research 7, 368-372 doi:10.1007/s12026-0189032-5

10. A. Rodriguez, M. Atikuzzaman, International Journal of Molecular Sciences 20, 502522 doi:10.3390/ijms20030513

11. V. Battist, L. Maders, M. Bagatini, E. Battisti, Biomedicine \& Pharmacotherapy 67, 203-208 (2013) doi: 10.1016/j.biopha.2012.12.004

12. V. Kim, A. Pham-Huy, E. Grunebaum, Journal of Allergy and Clinical Immunology 143, 403-405 (2019) DOI: 10.1016/j.jaci.2018.04.029

13. B. Overley-Adamson, J. Baez, Feline internal medicine 7, 578-584 (2016) doi:10.1016/B978-0-323-22652-3.00059-1.

14. O. Garden, S. Volk, N. Masson, J. Perry, The Veterinary Journal 240, 6-13 (2018) DOI:10.1016/j.tvj1.2018.08.008

15. A. Matosab, C. Baptistaac, M. Gärtnerad, The Veterinary Journal 193, $24-31$ (2016) doi:10.1016/j.tvj1.2011.12.019

16. H.W. Lee, P. Gangadaran, S. Kalimuthu, B.C. Ahn, Advances in Molecular Imaging Strategies for in Vivo Tracking of Immune Cells, BioMed Research International, 1946585 (2016) doi: 10.1155/2016/1946585

17. J.R. Scalea, Y. Tomita, C.R. Lindholm, W. Burlingham, Transplantation tolerance induction: Cell therapies and their mechanisms, Frontiers in Immunology 7(87) (2016) doi: 10.3389/fimmu.2016.00087 